\title{
Correlation between total lipids, linolenic acid and membrane injury under PEG-induced dehydration in leaves of Vigna genotypes differing in drought resistance
}

\author{
Paula Scotti-Campos ${ }^{1,2 *}$, Anh-Thu Pham-Thi ${ }^{3}$ \\ ${ }^{1}$ Lab, Fisiologia Vegetal, Unidade de Biotecnologia e Recursos Genéticos, Instituto Nacional de Investigação Agrária e Veterinária (INIAV), Av. \\ República, Quinta do Marquês, Oeiras, Portugal, ${ }^{2}$ GeoBioTec, Faculdade de Ciências e Tecnologia, Universidade Nova de Lisboa, Campus da \\ Caparica, 2829-516 Monte de Caparica, Portugal, ${ }^{3}$ Lab, Ecophysiologie Moléculaire, UMR BIOEMCO CNRS7618, Université Paris-Est Créteil, \\ 60 Av du Général de Gaulle, Créteil, France
}

\section{A B S TR A C T}

Membrane lipids contain trienoic fatty acids which enhance fluidity, an essential feature for optimal membrane performance. However highly unsaturated molecules are prone to lipoperoxidation processes. In $V$. unguiculata, linolenic acid (C18:3) accounts for more than $90 \%$ of the total fatty acids of galactolipids. High C18:3 contents causes galactolipids molecules, especially monogalactosyl-diacylglycerol (MGDG), to become more susceptible to drought-induced peroxidative or enzymatic degradation. In this work 8 Vigna genotypes differing in drought resistance in the field were compared to search for an eventual correlation between genotypes ability to resist to water stress and some characteristics of their membrane lipids in well-watered plants. Plants were grown in a greenhouse with semi-controlled environmental conditions, and kept fully hydrated. Leaves were collected from one month old plants to perform electrolyte leakage test under PEG-induced dehydration and lipid analysis. Results showed that both a reduced amount of total lipids, which reflects a small amount of membranes, and a reduced amount of C18:3 in MGDG, which indicates a low membrane fluidity, were strongly correlated with a high membrane resistance to dehydration, and therefore seem to be useful screening tools for drought-tolerant genotypes. Taking into account what is known concerning drought resistance of the genotypes under study, it was also concluded that the degree of membrane resistance to osmotic stress could be extrapolated to drought resistance in the field.

Keywords: Dehydration tolerance; Galactolipids; Membrane leakage; Osmotic stress; Polyethylene glycol; Vigna spp. germplasm

Abbreviations: DGDG, digalactosyl-diacylglycerol; DW, dry weight; FW, fresh weight; I\%, injury index; MGDG, monogalactosyldiacylglycerol; PEG, polyethylene glycol; PG, phosphatidylglycerol; TFA, total fatty acids; TL, total lipids; C16:1t, trans-hexadecenoic acid; C18:2, linoleic acid; C18:3, linolenic acid.

\section{INTRODUCTION}

Membrane lipids play an essential role in cells metabolism, maintaining cell integrity and ensuring the activity of membrane-bound proteins (Leshem, 1992). Under stress conditions, they undergo modifications which either enable them to acclimate to the new environment or lead to irreversible injury and cell death (Kuiper, 1985; Harwood, 1998). Qualitative and quantitative changes of membrane lipids have been involved in adaptation to many abiotic stresses, such as cold (Partelli et al., 2011; Scotti-Campos et al., 2014a), heat (Scotti-Campos et al., 2014b), aluminium toxicity (Huynh et al., 2012) and drought (Pham Thi et al., 1990; Matos et al., 2010; Scotti-Campos et al., 2013), among others.

In the case of drought stress, studies on lipid and fatty acid composition of leaf membranes revealed monogalactosyldiacylglycerol (MGDG) as the the most susceptible lipid. This galactolipid contains high percentages of linolenic acid (C18:3) (Pham Thi et al. 1982; Monteiro de Paula et al., 1990), which is the main fatty acid component of

\footnotetext{
${ }^{*}$ Corresponding author:

Paula Scotti-Campos, Lab. Fisiologia Vegetal, Unidade de Biotecnologia e Recursos Genéticos, Instituto Nacional de Investigação Agrária e Veterinária (INIAV), Av. República, Quinta do Marquês, 2784-505 Oeiras, Portugal. Phone: 003512948573, Mobile: 351 965146855,

E-mail: paula.scotti@iniav.pt
} 
chloroplast membranes, and, apparently, a major target of drought injury. In fact, its content in leaf cells dramatically decreased under water deficit, due to an inhibition of the biosynthesis of linoleic acid (C18:2) and C18:3 (Pham Thi et al., 1987), and to degradative processes (Monteiro de Paula et al., 1993). These were possible related to the drought activation of MGDG-hydrolases (El-Hafid et al., 1989; Sahsah et al., 1998), and to the fact that polyunsaturated fatty acids are preferential substrates for peroxydative breakdown (Ferrari-Iliou et al., 1993). Drought-tolerant plants do resist better to these degradative processes than drought-susceptible plants (Pham Thi et al., 1990; Monteiro de Paula et al., 1993; Campos and Pham Thi, 1995), raising the question of which mechanisms could be responsible for this better resistance capacity. The answers are complex, including not only those concerning lipids themselves, but also those involving other aspects of cell metabolism (Gigon et al., 2004; Torres-Franklin et al., 2007; Matos and Pham Thi, 2009, Scotti-Campos et al., 2013).

In this work we tried to search for an eventual correlation between the ability of plants to resist to water stress and some characteristics of their membrane lipids. Several authors have highlighted the basic role of unsaturated phosphatidylglycerol (PG) in plants tolerance to cold (Murata, 1983; Norman et al., 1984; Roughan, 1985; Murata et al., 1992; Murata and Wada, 1995). In the case of drought stress, we investigated the hypothesis that C18:3 plays a central role in plants resistance to drought.

In order to confirm this hypothesis, we choose eight Vigna species and varieties from different origins, differing in their drought resistance. Cowpeas are widely distributed food grain legume in African countries, where they are grown as a subsistence crop for home use. They are extensively grown in South-East Asia and in Latin America (Onwueme and Sinha, 1991), and are also largely spread in Southern Europe, namely in Portugal (Pinto Ricardo and Baeta, 1982). They are a warm-weather annual crop, therefore withstanding heat better than most other legumes and being considered very drought-resistant (Van der Maesen and Somaatmadja, 1989; Onwueme and Sinha, 1991). Vigna unguiculata may be grown under lower rainfall and more adverse conditions than Phaseolus vulgaris, and is able to develop in a wide variety of soils, provided they are well drained. In Portugal it is grown as a spring dryland crop, and it development relies on the last spring rainfalls, as well as on available soil water content (Prof. J. Vieira da Silva, personal communication), and can be cropped in regions of reduced rainfall and facing serious desertification problems (Fadigas, 1986).

Cowpeas constitute an important protein source (Pandey et al., 1984), containing high amounts of vitamins B1 (thiamine) and B3 (niacin), and calcium (Onwueme and Sinha, 1991). They present high contents of essential amino acids (lysin and tryptophan), being deficient in methionine and cysteine, contrarily to what happens in cereals, what explains the complementary roles of these crops from a nutritional point of view (Pinto Ricardo and Baeta, 1982; Onwueme and Sinha, 1991). Fresh and dried seeds, immature pods, young shoots and leaves may be used in a number of ways. Cowpeas also provide feed, forage, hay and silage for livestock, and green manure and cover for maintaining the productivity of soils. When intercropped with cereals, they compensate for the loss of nitrogen removed by the latter (Onwueme and Sinha, 1991).

The genus Vigna includes many species and varieties from arid and semi-arid regions (Van der Maesen and Somaatmadja, 1989), frequently presenting a good adaptation capacity to conditions of reduced water availability. Like the genus Phaseolus, it belongs to the tribe Phaseolae, subfamily Papilionideae and family Leguminosae (Fabaceae). According to Onwueme and Sinha (1991), it includes 170 species. Some of these are commonly cultivated and are considered important grain legumes all over the world, as is the case of cowpea, Vigna unguiculata (L.) Walp. This species was originated in Africa, and two centres of diversity appear to exist, which contains wild and cultivated forms: one in West Africa for Vigna unguiculata ssp. unguiculata, and another in India and South-East Asia for Vigna unguiculata ssp. cylindrica and Vigna unguiculata ssp. sesquipedalis (Van der Maesen and Somaatmadja, 1989; Smartt, 1990).

Vigna unguiculata ssp. dekindtiana, which occurs in Africa, has been considered the wild ancestor of cultivars which were domesticated in the region of Ethiopia, in West Africa or even throughout the African savannah, more than 4000 years ago. The earliest cultivars in Africa were probably spreading, short-day types of subspecies unguiculata. It is believed that this subspecies reached India around $1500 \mathrm{BC}$. In India, the two other subspecies, cylindrica and sesquipedalis, were selected from it. Cowpeas reached southern Europe from Asia around 330 BC, and the New World in the seventeenth century from West Africa and Europe (Baudoin and Maréchal, 1985; Onwueme and Sinha, 1991).

Another important gene pool belonging to the genus Vigna are the Asiatic species, namely Vigna radiata (L.) Wilczek, Vigna mungo (L.) Hepper, Vigna umbellata (Thunb.) Ohwi \& Ohashi, Vigna angularis (Willd.) Ohwi \& Ohashi, Vigna aconitifolia (Jacq.) Maréchal, Vigna trilobata (L.) Verdc. and Vigna vexillata (L.) A. Rich (Baudoin and Maréchal, 1985; Smartt, 1990). Smartt (1985) attributes a special importance to the species Vigna glabrescens Maréchal, Mascherpa 
\& Stainier, because it is a polyploid that combines the genomes of Vigna radiata and Vigna umbellata. Vigna radiata and Vigna mungo also constitute important grain legumes, and are extensively grown in India. The majority of these species are drought resistant, as is the case of Vigna mungo and Vigna angularis, and some withstand drought well by curtailing the period from flowering to maturity, as is the case in Vigna radiata (Van der Maesen and Somaatmadja, 1989).

In what concerns drought resistance a large variability exists within the cultivated subspecies of Vigna unguiculata L., as well as within the different Vigna species. Furthermore, the study of wild species is necessary to screen for drought tolerant genotypes and increase knowledge concerning the physiological mechanisms underlying a better plant adaptation to water stress conditions. The understanding of such mechanisms may highlight specific cellular features, which might be used for the genetic manipulation of cultivated plants, without affecting production (Hughes et al., 1992). In the present study the genus Vigna was considered as a particularly suitable germplasm to study the mechanisms involved in cellular responses to dehydration.

Some of the agronomical characteristics of the genotypes used in this study, namely what is known in the literature about their resistance to drought in the field, as well as their geographical distribution, are indicated in Table 1.

To test the degree of protoplasmic resistance to water stress, drought was mimicked by submitting leaf discs to an osmotic solution, and the injury caused to the membranes was evaluated by measuring the electrolyte efflux, as previously reported by several authors (Simon, 1974; Blum and Ebercon, 1981; Vasquez-Tello et al., 1990). Analysis of polar lipids content and fatty acids composition in leaves of well-hydrated plants were also performed, in an attempt to correlate membrane lipid features with different degrees of membrane resistance to dehydration.

\section{MATERIALS AND METHODS}

\section{Plant material}

For this study seeds of 8 Vigna genotypes were chosen and classified according to what is known in the literature about their resistance to drought in the field (Table 1).

Vigna germplasm was obtained from the collection of Professor Maréchal (University of Gembloux, Belgium). Seeds were germinated on paper soaked with distilled water, in Petri dishes, in the dark, at room temperature. Seedlings were then transferred to pots containing a
Table 1: Geographical distribution, agronomical characteristics and degree of drought resistance in the field of 8 Vigna genotypes

- Vigna glabrescens

Vg

- Vigna aconitifolia

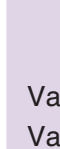

Va1
Va2

- Vigna vexillata

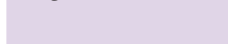

Vv

- Vigna mungo

$\mathrm{Vm}$

- Vigna radiata

Vr

- Vigna unguiculata

ssp. dekindtiana

Vu1

- Vigna unguiculata

ssp. unguiculata

cv. 1183

Vu3 Wild species from dry regions of South-East Asia (Philippines) Very resistant

Cultivated in arid and semi-arid regions of North-East India, where it grows in dry, poor and sandy soils, in regions where rainfall does not exceed $750 \mathrm{~mm}$ per year. Wild, very resistant. Cultivated, moderately resistant A tuberous bean cultivated in high altitudes of humid tropical zones of Africa and Asia, and presenting a moderate resistance to drought.

Moderately resistant

Cultivated in humid regions of India, where rainfall does not exceed $1000 \mathrm{~mm}$ per year Resistant

Widely cultivated in relatively dry regions. Moderately resistant.

Grows wild particularly in the sub-sahelian regions of Africa.

Resistant

Cultivated in humid regions of China.

Purseglove, 1968; Jain and Mehra, 1980; Singh and Rachie, 1985

mixture of fertilized peat and vermiculite $(1 / 1, v / v)$ and grown under semi-controlled environmental greenhouse conditions: temperature between $27-25^{\circ} \mathrm{C} / 21-19^{\circ} \mathrm{C}$ (day/night), $70 \%$ relative humidity, $14 \mathrm{~h}$ photoperiod and irradiance of 300 to $500 \mu \mathrm{mol} \mathrm{m} \mathrm{m} \mathrm{s}^{-1}$ at level of the first well developed leaf (provided by Philips SON/T 400W lamps). Plants were watered daily, and fed twice a week with a nutrient solution (BASF Hakaphos, $15 \%$ N, 11\% $\mathrm{P}, 15 \% \mathrm{~K})$. Samples were collected in plants presenting 5 to 7 well-developed leaves.

\section{Electrolyte leakage evaluation}

Twenty leaf discs $\left(0.8 \mathrm{~cm}^{2}\right)$ were floated for $4 \mathrm{~h}$ on an osmotic solution (PEG MW 600, -1.13 MPa). They were then washed and floated on distilled water for $24 \mathrm{~h}$. After $5 \mathrm{~h}$ of rehydration, electrolyte leakage from the leaf discs was monitored with a conductimeter (Tacussel CM02SJ6, France). Control discs were floated on distilled water instead of PEG solution. Relative damage was expressed using an injury index ( $\mathrm{I} \%$ ) calculated as $\mathrm{I} \%=[1-(\mathrm{T}-\mathrm{D} / \mathrm{T}-\mathrm{W})] 100$, according to Scherbakova and Kacperska-Palacz (1980). D and W represent the conductivity of the electrolytes released by PEG-treated and control samples, respectively, and $\mathrm{T}$ the total electrolyte conductivity measured in the effusate after heating the control samples at $90^{\circ} \mathrm{C}$ for $2 \mathrm{~h}$, followed by cooling to room temperature. 


\section{Lipid analysis}

Leaves ( $2 \mathrm{~g}$ FW) were detached from well-watered plants, boiled for $2 \mathrm{~min}$ in $10 \mathrm{ml}$ distilled water, in order to inactivate lipolytic enzymes, and homogeneized in a mixture of chloroform/methanol/water $(1 / 1 / 1$, by vol.) to extract total lipids (TL), according to Allen et al. (1966). After centrifugation at $4500 \mathrm{~g}$ for $10 \mathrm{~min}$, the chloroform phase, containing total lipids, was collected and evaporated under a nitrogen flow. The dry residue was resuspended in $1 \mathrm{ml}$ ethanol/toluene $(1 / 4, \mathrm{v} / \mathrm{v})$ and stored at $-20^{\circ} \mathrm{C}$, until analysis. Aliquots of $100 \mu \mathrm{l}$ of the TL were saponified with the addition of $4 \mathrm{ml} 0.5 \mathrm{M} \mathrm{NaOH}$ in methanol, and heated at $65^{\circ} \mathrm{C}$ for 15 min. Fatty acids were methylated with $2 \mathrm{ml}$ of $\mathrm{BF}_{3}-$ methanol (Merck) followed by heating the mixture at $65^{\circ} \mathrm{C}$ for 15 min, according to Metcalfe et al. (1966). Prior to methylation, heptadecanoic acid (C17:0) was added as an internal standard (100 $\mu \mathrm{g}$ per sample) to allow quantitative determinations. The resulting fatty acids methyl esters were extracted by adding $2 \mathrm{ml}$ of water and $10 \mathrm{ml}$ of pentane to each sample, followed by a vigorous shaking. After removal and evaporation of the pentane phase under a nitrogen flow, each sample was ressuspended in 100-200 ul of hexane. Fatty acids methyl esters (FAME) were analysed using a gas chromatograph (Varian 3300, USA) coupled to a Varian 4290 integrator, and equipped with a hydrogen flame-ionization detector (GC-FID). Separation was performed with a fused silica capillary column Supelcowax 10 (0.32 mm i.d. x 30 m (Supelco, USA) coated with bonded PEG polymer at a thickness of $0.25 \mu \mathrm{m}$. Column temperature was programmed to

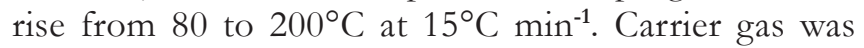
helium with a flow rate of $1 \mathrm{ml} \mathrm{min}{ }^{-1}$, at a split ratio of 1:100 of the sample. Injector and detector temperatures were $250^{\circ} \mathrm{C}$ and $270^{\circ} \mathrm{C}$, respectively. Individual fatty acids were identified by comparison with known standards (Sigma). Total fatty acids (TFA) corresponded to the sum of individual fatty acids. Lipid classes separation was performed by two successive one dimensional thin layer chromatography (TLC), as described in Scotti-Campos et al. (2013). Samples were applied on silica gel G60 plates (Merck), and eluted in chloroform/ acetone/methanol/acetic acid/water (50/20/10/10/5, by vol.) according to Lepage (1967), and subsequently in petroleum ether/diethyl ether/acetic acid (70/30/0.4, by vol.), according to Mangold (1961). After spraying with primuline $0.01 \%$ in $80 \%$ acetone and visualizing under UV light, the bands were scraped off, saponified, methylated and analysed by GC-FID, as described above.

\section{Statistical analysis}

The data were analysed statistically using a two-way ANOVA, applied to the various measured and calculated parameters, followed by a Tukey test for mean comparison between genotypes (for a 95\% confidence level). Statistical correlations between $\mathrm{I} \%$ and various lipid parameters were calculated.

\section{RESULTS}

The 8 Vigna genotypes showed different degrees of membrane resistance to osmotic stress (Table 2). Considering that a greater electrolyte leakage corresponds to a higher membrane susceptibility, $V$. glabrescens $(\mathrm{Vg})$ and $V$. aconitifolia Va1 showed the lowest injury index (I\%) values, and therefore the most resistant membranes. On the contrary V. unguiculata Vu3 (cv. 1183) showed the highest loss of membrane selectivity, and was considered the most sensitive genotype as regards this feature, what agrees with previous results (Scotti-Campos et al., 2013).

Under control conditions some lipid parameters, which are meaningful from a metabolic or ultrastructural point of view, were analysed. The total lipids (TL) content, obtained from the TFA, and expressed on a dry weight basis, estimates the amount of membrane (Harwood 1980). The relative distribution of lipid classes, expressed as percentage of the TL, gives indications on specific membrane features (Mazliak, 1983; Harwood, 1998). Galactolipid/phospholipid ratio, indicates the abundance of chloroplast membranes in relation to extra-chloroplastic ones (Douce and Joyard, 1980). MGDG/DGDG ratios related to preservation of membrane integrity due to stable DGDG bilayer configuration (Leshem, 1992; TorresFranklin et al., 2007). The fatty acid composition of the lipid classes, in particular the amount of C18:3, strongly contributes to the degree of unsaturation, therefore playing a role in the fluidity of the lipid matrix (Webb and Green, 1991; Harwood, 1998). Phosphatidylglycerol (PG) is a major phospholipid in chloroplasts, and the amount of C16:1t in PG, is known to have important functions in photosynthetic membranes (Huner et al., 1989; Murata et al., 1992; Siegenthaler and Trémolières, 1998; ScottiCampos et al., 2014a).

\begin{tabular}{|c|c|}
\hline Genotype & Injury index (I\%) \\
\hline Vigna glabrescens $(\mathrm{Vg})$ & $2.7 \pm 0.5$ \\
\hline Vigna aconitifolia (Va1) & $3.2 \pm 0.2$ \\
\hline Vigna vexillata (Vv) & $6.9 \pm 0.9$ \\
\hline Vigna unguiculata (Vu1) & $7.5 \pm 0.5$ \\
\hline Vigna mungo (Vm) & $10.4 \pm 1.0$ \\
\hline Vigna aconitifolia (Va2) & $10.9 \pm 2.2$ \\
\hline Vigna radiata (Vr) & $13.5 \pm 1.2$ \\
\hline Vigna unguiculata (Vu3) & $18.9 \pm 1.0$ \\
\hline
\end{tabular}

Results are means \pm SE $(n=3)$ 
As regards correlations between membrane resistance (Table 2) and lipid parameters, it was observed that I $\%$ was strongly correlated with total leaf lipid contents (Fig. 1), and with the amount of C18:3 in MGDG (Fig. 2).

No significant correlations were found between $\mathrm{I} \%$ and the distribution of lipid classes, in particular with the galactolipids/phospholipids ratios (results not shown). This indicates that there were no differences among the 8 Vigna genotypes concerning the relative abundance of the chloroplast membranes with regard to the extrachloroplastic compartment. Linolenic acid percentages in total lipids as well as in phospholipids, were not related with cell susceptibility to dehydration (correlations not presented).

\section{DISCUSSION}

Cell membranes are major targets of environmental stresses (Leshem, 1992) and in vitro screening tests for membrane permeability may contribute for genotypes selection under different stress conditions. Electrolyte leakage test has been previously used to evaluate membrane tolerance to dehydration (Vasquez-Tello et al., 1990; Matos et al., 2010; Scotti-Campos et al., 2013). Altered membrane permeability may result in increased leakage from cells due to the appearance of heterogeneous membrane domains as regards lipid phases and configurations (Leshem, 1992), or to damage of membrane components, namely within the lipid matrix (Harwood, 1998). The electrolyte leakage from leaf discs of 8 Vigna genotypes submitted to a PEGinduced dehydration showed correlations with some of the characteristics of their membrane lipids. It was found that leaf discs presenting a higher resistance to osmotic stress contained lower lipid contents (Fig. 1) and, hence, less membrane (on a DW basis), and that their thylakoids were apparently less rich in dilinolenoyl-MGDG (Fig. 2), the major polyunsaturated galactolipid of the chloroplast membranes. This is supported by our previous works using different plant species, where a relation was also found between drought resistance at cell level and the percentage of linolenic acid of the membranes (Pham Thi et al., 1990). Phaseolus vulgaris $\mathrm{cv}$. carioquinha (drought-susceptible) presented a high C18:3 percentage (95\%) in the MGDG from leaves (Pham Thi et al., 1990), whereas MGDG from leaves of the desiccation-tolerant species Ramonda nathaliae and Ramonda serbica contained much lower $(55 \%$ and $64 \%$, respectively) C18:3 percentages (Stevanovic et al., 1992).

How could these lipid parameters be related to drought resistance? One of the most current consequences of drought is the drastic MGDG decrease in leaves submitted to water deficit (Pham Thi et al., 1982, Monteiro de Paula

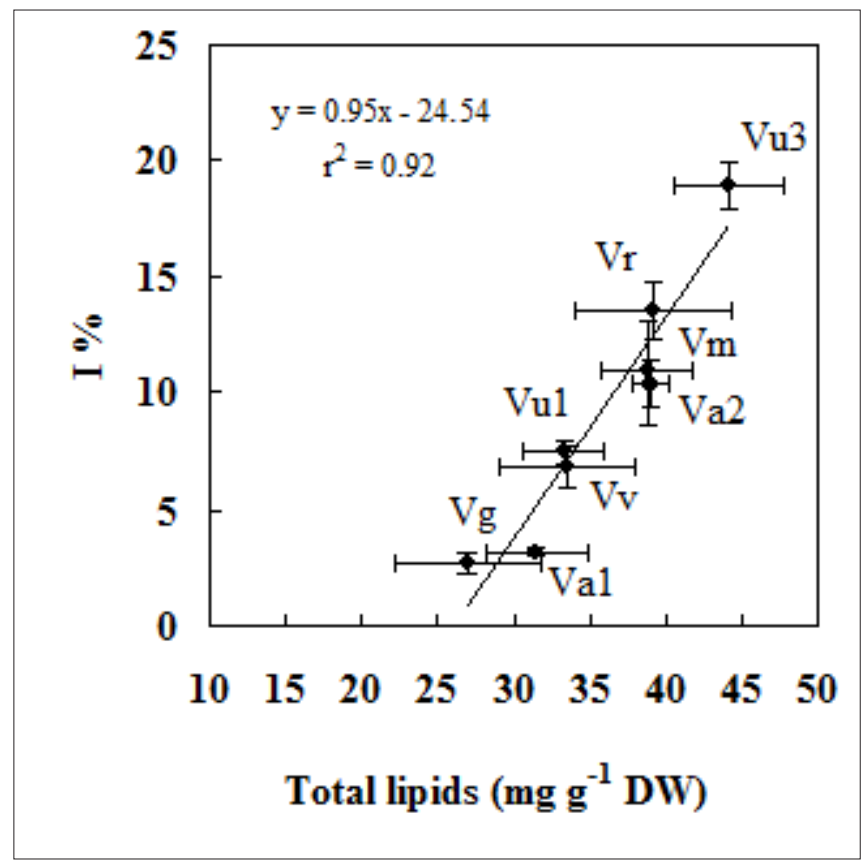

Fig 1. Linear regression correlation between injury index (I\%) of PEG-dehydrated leaf discs and leaf total lipid content in well irrigated plants of 8 Vigna genotypes. $\mathrm{r}^{2}$, correlation coefficient; $\mathrm{Vg}$, V. glabrescens; Va, V. aconitifolia; Vv, V. vexillata; Vm, V. mungo; Vr, $V$. radiata; $\mathrm{Vu}, V$. unguiculata. Results are means $\pm \mathrm{SE}(\mathrm{n}=3)$.

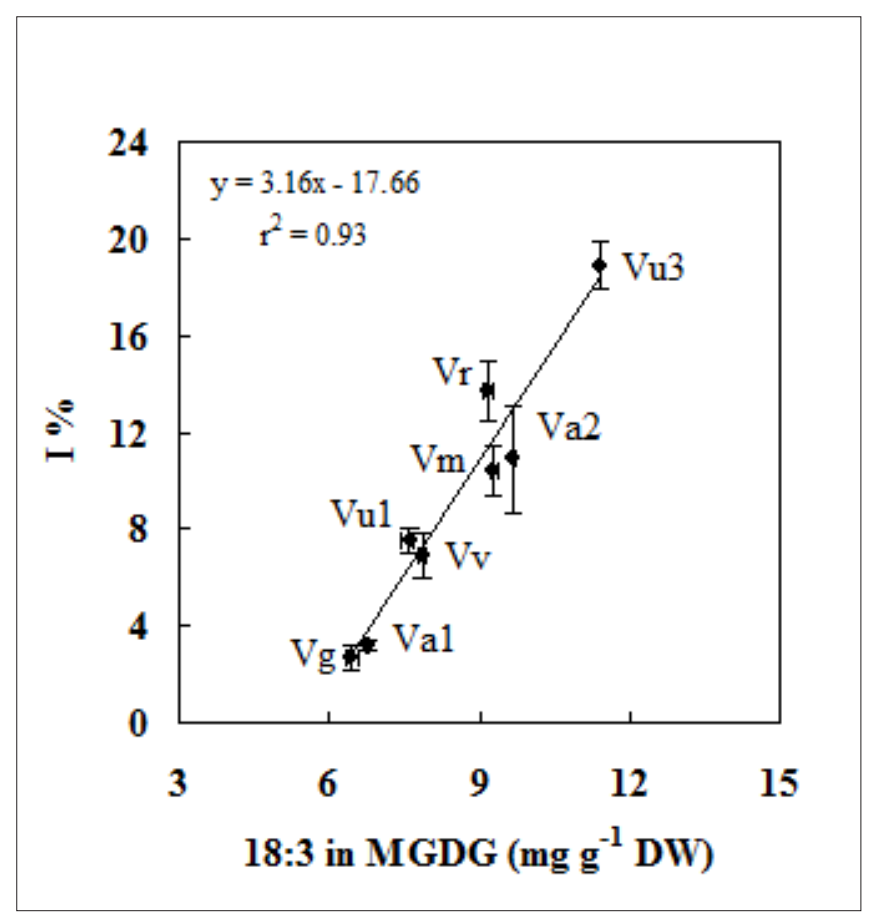

Fig 2. Linear regression correlation between injury index (I\%) of PEG-dehydrated leaf discs and linolenic acid (C18:3) content in monogalactosyl-diacylglycerol (MGDG) in leaves of well irrigated plants of 8 Vigna genotypes. $\mathrm{r}^{2}$, correlation coefficient. Symbols for genotypes as in Fig. 1. Results are means \pm SE $(n=3)$.

et al., 1990). The particular susceptibility of that lipid in leaves, is due to the occurrence in its molecule of 
triunsaturated fatty acids, namely C18:3. Double bonds are chemically very reactive and it has been demonstrated that C18:3 is the main target for peroxydative (Frankel, 1985; Ferrari-Iliou et al., 1993) and hydrolytic (El-Hafid et al., 1989) lipid degradation processes. On the other hand, it could be remarked that the polar headgroup also plays a role in the susceptibility of the molecule, since DGDG, the other major galactolipid of the chloroplast membrane, is also highly unsaturated, but is much less degraded under water stress conditions (Scotti-Campos et al., 2013). The fact that cell membranes of the resistant genotypes contain less C18:3 may confer them a lower susceptibility to degradative processes, as reported under high irradiation (Ramalho et al., 1998), drought (Matos et al., 2010), heat (Dias et al., 2010) and cold (Campos et al., 2003; Partelli et al., 2011) stress conditions.

However thylakoids are particularly rich in polyunsaturated MGDG and MGDG molecules which play an important role in photosynthetic processes (Siegenthaler and Trémolières, 1998). Moreover, polyunsaturated fatty acids are responsible for the great fluidity of the chloroplast membrane, thus ensuring the good functioning of the photosystems (Bishop et al., 1979; Gounaris et al., 1983). There seems to be an apparent opposition between a good fluidity and high thylakoid content, and membrane tolerance to dehydration. The fact that the chloroplast membrane of resistant genotypes contained less polyunsaturated MGDG molecules could be related to the well-known lower yield of drought-resistant plants compared to sensitive ones when they are placed in irrigated conditions (Parsons, 1982). We hypothesized that the price to pay for a greater stability, id est a greater tolerance, could be a reduced photosynthetic efficiency. However, under optimum irrigation, no relation was found between a higher membrane stability and an intrinsic lower photosynthetic activity, since cv. 1183 and $\mathrm{Vg}$ showed similar photosynthetic capacity $\left(\mathrm{A}_{\max }\right)$ values (Campos et al., 1999).

Another question concerns the possibility that membrane tolerance is related to drought resistance of the whole plant. From the geographical distribution of the 8 Vigna genotypes and electrolyte leakage results (Table 1), it could be inferred that membrane resistance to PEG-induced dehydration seems to be related to drought resistance of the whole plant in the field.

In general, plants which present mechanisms of drought escape do not show strong tolerance at cellular level (Levitt, 1980). It would be interesting to introduce in drought susceptible plants genes which induce a better drought tolerance. One of the possible ways could be to modify their lipid metabolism in order to obtain more saturated MGDG molecules. Another possibility may consist in the inhibition of degradative enzymes responsible for the breakdown of polar lipids. A third way could be the reinforcement of antioxidative molecules that can protect the lipids from oxidation caused by the overproduction of reactive oxygen molecules (ROS). In fact, oxidative stress is often triggered as a secondary stress, resulting from a decreased ability to use irradiance energy through photochemistry due to environmental stressed conditions. Nevertheless both a reduced amount of total lipids, which reflects a small amount of membranes, and a reduced amount of C18:3 in MGDG, which indicates lower membrane fluidity, seem to constitute useful indexes for screening drought-tolerant genotypes.

\section{Authors contributions}

Both the authors of the paper contributed equally to the writing of the paper and were involved in the overall planing and supervision of the work.

\section{REFERENCES}

Allen, C. F., P. Good, H. S. Davis, P. Chisum and S. D. Fowler. 1966. Methodology for the separation of plant lipids and application to spinach leaf and chloroplast lammelae. J. Am. Oil Chem. Soc. 43: 223-230.

Baudoin, J. P. and R. Maréchal. 1985. Genetic diversity in Vigna. In: Singh, S. R., K. O. Rachie, (Eds.), Cowpea Research, Production and Utilization, John Wiley \& Sons, New York, Pp. 3-9.

Bishop, D. G., J. R. Kenrick, J. H. Bayston, A. S. MacPherson, S. R. Johns and R. I. Willing. 1979. The influence of fatty acid unsaturation on fluidity and molecular packing of chloroplast membrane lipids. In: Lyons, J. M., D. Graham and J. K. Raison, (Eds.), Low Temperature Stress in Crop Plants. The Role of the Membrane, Academic Press, New York, Pp. 375-390.

Blum, A. and A. Ebercon. 1981. Cell membrane stability as a measure of drought and heat tolerance in wheat. Crop Sci. 21: 43-47.

Campos, P. S., J. C. Ramalho, J. A. Lauriano, M. J. Silva and M. C. Matos. 1999. Effects of drought on photosynthetic performance and water relations of four Vigna genotypes. Photosynthetica. 36: 79-87.

Campos, P. S., V. L. Quartin, J. C. Ramalho and M. A. Nunes. 2003. Electrolyte leakage and lipid degradation account for cold sensitivity in leaves of Coffea sp. plants. J. Plant Physiol. 160: 283-292.

Campos, P. and A. T. Pham Thi. 1995. Effects of drought stress on enzymatic breakdown of galactolipids in cowpea (Vigna unguiculata L.) leaves. In: Kader, J. C. and P. Mazliak, (Eds.), Plant Lipid Metabolism, Kluwer Academic Publishers, Dordrecht, Pp. 426-428.

Dias, A. S., M. G. Barreiro, P. S. Campos, J. C. Ramalho and F. C. Lidon. 2010. Wheat cellular membrane thermotolerance under heat stress. J. Agric. Crop Sci. 196: 100-108.

Douce, R. and J. Joyard. 1980. Plant galactolipids. In: Stumpf, P. K. and E. E. Conn, (Eds.), The Biochemistry of Plants. A Comprehensive Treatise, Vol. IV. Academic Press, New York, Pp. 321-362.

El-Hafid, L., A. T. Pham Thi, Y. Zuily-Fodil and J. Vieira da Silva. 1989. Enzymatic breakdown of polar lipids in cotton leaves under water stress. Degradation of monogalactosyl-diacylglycerol. 
Plant Physiol. Biochem. 27: 495-502.

Fadigas, L. 1986. Desertificação e empobrecimento. O caso português. Rev. Ciên. Agrár. 9: 29-36.

Ferrari-lliou, R., A. D'Arcy-Lameta, J. P. Iliou, A. T. Pham Thi, F. Monteiro de Paula, J. Vieira Silva and P. Mazliak. 1993. In vitro photodynamic lipid peroxidation of total lipophilic extracts from leaves of bean plants. Biochim. Biophys. Acta 1166: 48-54.

Frankel, E. N. 1985. Chemistry of free radical and singlet oxidation of lipids. Prog. Lip. Res. 23:197-221.

Gigon, A., A. R. Matos, D. Laffray, Y. Zuily-Fodil and A. T. Pham-Thi. 2004. Effect of drought stress on lipid metabolism in the leaves of Arabidopsis thaliana (Ecotype Columbia). Ann. Bot. 94(3): 345-351.

Gounaris, K., D. A. Mannock, A. Sen, A. P. R. Brain, W. P. Williams and P. J. Quinn. 1983. Polyunsaturated fatty acyl residues of galactolipids are involved in the control of bilayer/non bilayer lipid transitions in bilayer plant chloroplasts. Biochim. Biophys. Acta. 732: 229-242.

Harwood, J. 1980. Plant acyl lipids: Structure, distribution and analysis. In: Stumpf, P. K. and E. E. Conn, (Eds.), The Biochemistry of Plants. A Comprehensive Treatise, Vol. IV. Academic Press, New York, Pp. 1-55.

Harwood, J. L. 1998. Involvement of chloroplast lipids in the reaction of plants submitted to stress. In: Siegenthaler, P. A. and N. Murata, (Eds.), Lipids in Photosynthesis: Structure, Function and Genetics, Series Advances in Photosynthesis, Vol. 6. Kluwer Academic Publishers, Dordrecht, Pp. 287-302.

Hughes, S. G., J. A. Bryant and N. Smirnoff. 1992. Molecular biology: Application to studies of stress tolerance. In: Jones, H. G., T. J. Flowers and M. B. Jones, (Eds.), Plants Under Stress, Cambridge University Press, Cambridge, Pp. 131-155.

Huner, N., J. P. Williams, E. E. Maissan, E. G. Myscich, M. Krol, A. Laroche and J. Singh. 1989. Low temperature-induced decrease in trans- $\Delta^{3}$-hexadecenoic acid content is correlated with freezing tolerance in cereals. Plant Physiol. 89: 144-150.

Huynh, V., A. Repellin, Y. Zuily-Fodil and A. T. Pham-Thi. 2012. Aluminium stress response in rice: Effects on membrane lipid composition and expression of lipid biosynthesis genes. Physiol. Plant. 146: 272-284.

Jain, H. K. and K. L. Mehra. 1980. Evolution, adaptation, relationships and uses of the species of Vigna cultivated in India. In: Summerfield, R. J. and A. H. Bunting, (Eds.), Advances in Legume Science, HMSO, London, Pp. 459-468.

Kuiper, J. P. C. 1985. Environmental changes and lipid metabolism of higher plants. Physiol. Plant. 64: 118-122.

Lepage, M. 1967. Identification and composition of turnip root lipids. Lipids. 2: 244-250.

Leshem, Y. 1992. Plant membranes: A Biophysical Approach to Structure, Development and Senescence, Kluwer Academic Publishers, Dordrecht.

Levitt, J. 1980. Responses of Plants to Environmental Stresses. Water, Radiation, Salt and Other Stresses, Vol. II. Academic Press, New York.

Mangold, H. K. 1961. Thin layer chromatography of lipids. J. Am. Oil Chem. Soc. 38: 708-727.

Matos A. R. and A. T. Pham-Thi. 2009. Lipid deacylating enzymes in plants: Old activities, new genes. Plant Physiol. Biochem. Special Issue Plant Lipids. 47: 491-503.

Matos, M. C., P. S. Campos, J. A. Passarinho, J. N. Semedo, N. M. Marques, J. C. Ramalho and C. P. Ricardo. 2010. Drought effect on photosynthetic activity, osmolyte accumulation and membrane integrity of two Cicer arietinum genotypes.
Photosynthetica. 48: 303-312.

Mazliak, P. 1983. Plant membrane lipids: changes and alterations during aging and senescence. In: Morris, L., (Ed.), Post-Harvest Physiology and Crop Preservation, Nato Advanced Study Institutes Series, Plenum Press, New York, Pp. 123-140.

Metcalfe, L. D., A. A. Schemitz and J. R. Pelka, 1966. Rapid preparation of fatty-acid esters from lipids for gas chromatographic analysis. Anal. Chem. 38: 514-515.

Monteiro de Paula, F., A. T. Pham Thi, Y. Zuily-Fodil, R. Ferrari-lliou, J. Vieira da Silva and P. Mazliak. 1993. Effects of water stress on the biosynthesis and degradation of polyunsaturated lipid molecular species in leaves of Vigna unguiculata. Plant Physiol. Biochem. 31: 707-715.

Monteiro de Paula, F., A. T. Pham Thi, J. Vieira da Silva, A. M. Justin, C. Demandre and P. Mazliak, 1990. Effects of water stress on the molecular species composition of polar lipids from Vigna unguiculata leaves. Plant Sci. 66: 185-193.

Murata, N. and H. Wada. 1995. Acyl-lipid desaturases and their importance in the tolerance and acclimatization to cold of cyanobacteria. Biochem. J. 308: 1-8.

Murata, N. 1983.Molecular species composition of phosphatidylglycerols from chilling-sensitive and chillingresistant plants. Plant Cell Physiol. 24: 81-86.

Murata, N., O. Ishizaki-Nishizawa, S. Higashi, H. Hayashi, Y. Tasakaand AND I. Nishida. 1992. Genetically engineered alteration in the chilling sensitivity of plants. Nature. 356: 710-714.

Norman, H. A., C. Mc Millan and G. A. Thompson Jr. 1984. Phosphatidylglycerol molecular species in chilling-sensitive and chilling-resistant populations of Avicennia germinans L. Plant Cell Physiol. 25: 1437-1444.

Onwueme, I. C. and T. D. Sinha. 1991. In: Field crop production in tropical Africa. Principles and Practice, C.T.A., The Netherlands.

Pandey, R. K., W. A. T. Herrera and J. W. Pendleton. 1984. Drought response of grain legumes under irrigation gradient: I. Yield and yield components. Agron. J. 76: 549-553.

Parsons, L. R. 1982. Plant responses to water stress. In: Christiansen, M. N., C. F. Lewis, (Eds.), Breeding Plants for Less Favorable Environments, John Wiley and Sons, New York.

Partelli, F. L., P. Batista-Santos, P. Scotti-Campos, I. P. Pais, V. L. Quartin, H. D. Vieira and J. C. Ramalho. 2011. Characterization of the main lipid components of chloroplast membranes and cold induced changes in Coffea sp. Environ. Exp. Bot. 74: 194-204.

Pham Thi, A. T., C. Borrel-Flood and J. Vieira da Silva. 1982. Effects of water stress on lipid and fatty acid composition of cotton leaves. In: J. F. G. Wintermans and P. J. C. Kuiper, (Eds.), Biochemistry and metabolism of plant lipids. Elsevier Science Publishers, Amsterdam, Pp. 451-454.

Pham Thi, A. T., C. Borrel-Flood, J. Vieira da Silva, A. M. Justin and P. Mazliak. 1987. Effects of drought on [1-14C]-oleic and [1-14C]-linoleic acid desaturation in cotton leaves. Physiol. Plant. 69: 157-159.

Pham Thi, A. T., J. V. da Silva and P. Mazliak. 1990. The role of membrane lipids in drought resistance of plants. Bull Soc. Bot. Fr. 137: 99-114.

Pinto Ricardo, C. P. and J. M. Baeta. 1982. Feijão. Importância agrícola e alimentar. Rev. Ciên. Agrár. 5: 59-80.

Purseglove, J. W. 1968. Tropical crops. Dicotyledons. Vol. II. Longmans, London.

Ramalho J. C., P. S. Campos, M. Teixeira and M. A. Nunes. 1998. Nitrogen dependent improvement of antioxidant systems and 
changes in lipid composition of chloroplast membranes in Coffea arabica plants submitted to high irradiance. Plant Sci. 135: 115-124.

Roughan, P. G. 1985. Phosphatidylglycerol and chilling sensitivity in plants. Plant Physiol. 77: 740-746.

Sahsah, Y., P. Campos, M. Gareil, Y. Zuily-Fodil and A. T. Pham Thi. 1998. Enzymatic degradation of polar lipids in Vigna unguiculata leaves and influence of drought stress. Physiol. Plant. 104: 577-586.

Scherbakova, A. and A. Kacperska-Palacz. 1980. Modification of stress tolerance by rehydration pretreatment in winter rape hypocotyls. J. Exp. Bot. 48: 560-563.

Scotti-Campos, P., I. P. Pais, F. L. Partelli, P. Batista-Santos and J. C. Ramalho. 2014a. Phospholipids profile in chloroplasts of Coffea spp. genotypes differing in cold acclimation ability. J. Plant Physiol. 171: 243-249.

Scotti-Campos, P., A. T. Pham-Thi, J. N. Semedo, I. P. Pais, J. C. Ramalho and M. C. Matos. 2013. Physiological responses and membrane integrity in three Vigna genotypes with contrasting drought tolerance. Emirates J. Food Agric. 25(12): 1002-1013.

Scotti-Campos, P., J. N. Semedo, I. P. Pais, M. Oliveira, J. Passarinho and J. C. Ramalho. 2014b. Heat tolerance evaluation of Portuguese old bread wheat varieties. Emirates J. Food Agric. Special Issue 'Wheat Landraces'. 26(2): 170-179.

Siegenthaler, P. A. and A. Trémolières. 1998. Role of acyl lipids in the function of photosynthetic membranes in higher plants. In: Siegenthaler, P.A. and N. Murata (Eds.), Lipids in Photosynthesis: Structure, Function and Genetics, Series Advances in
Photosynthesis, Vol. 6. Kluwer Academic Publishers, Dordrecht, The Netherlands, Pp. 145-173.

Simon, E. W. 1974. Phospholipids and plant membrane permeability. New Phytol. 73: 377-420.

Singh, S. R. and K. O. Rachie. 1985. Cowpea: Research, Production and Utilization. John Wiley \& Sons, New York.

Smartt, J. 1985. Evolution of grain legumes. III. Pulses in the genus Vigna. Expl. Agric. 21: 87-100.

Smartt, J. 1990. Grain Legumes. Evolution and Genetic Resources. Cambridge University Press, Cambridge.

Stevanovic, B., A. T. Pham Thi, F. M. de Paula and J. Vieira da Silva. 1992. Effects of dehydration and rehydration on the polar lipid and fatty acid composition of Ramonda species. Can. J. Bot. 70: 107-113.

Torres-Franklin, M. L., A. Gigon, D. F. Melo, Y. Zuily-Fodil and A. T. Pham-Thi. 2007. Drought stress and rehydration affect the balance between MGDG and DGDG synthesis in cowpea leaves. Physiol. Plant. 131: 201-210.

Van der Maesen, L. J. G. and S. Somaatmadja. 1989. Plant Resources of South-East Asia. N. 1, Pulses. Pudoc/Prosea, Wageningen.

Vasquez-Tello, A., Y. Zuily-Fodil, A. T. Pham Thi and J. V. da Silva. 1990. Electrolyte and inorganic phosphate leakages and soluble sugar content as physiological tests for screening resistance to water stress in Phaseolus and Vigna species. J. Exp. Bot. 41: 827-832.

Webb, M. S. and B. R. Green. 1991. Biochemical and biophysical properties of thylakoid acyl lipids. Biochem. Biophys. Acta. 1060: 133-158. 